\title{
Acute lung injury induced by whole gastric fluid: hepatic acute phase response contributes to increase lung antiprotease protection
}

Pedro Ayala ${ }^{1}$, Manuel Meneses ${ }^{4}$, Pablo Olmos ${ }^{2}$, Rebeca Montalva ${ }^{1}$, Karla Droguett ${ }^{3}$, Mariana Ríos ${ }^{3}$ and Gisella Borzone ${ }^{1 *}$

\begin{abstract}
Background: Gastric contents aspiration in humans is a risk factor for severe respiratory failure with elevated mortality. Although aspiration-induced local lung inflammation has been studied in animal models, little is known about extrapulmonary effects of aspiration. We investigated whether a single orotracheal instillation of whole gastric fluid elicits a liver acute phase response and if this response contributes to enrich the alveolar spaces with proteins having antiprotease activity.

Methods: In anesthetized Sprague-Dawley rats receiving whole gastric fluid, we studied at different times after instillation ( $4 \mathrm{~h}-7$ days): changes in blood cytokines and acute phase proteins (fibrinogen and the antiproteases alpha1-antitrypsin and alpha2-macroglobulin) as well as liver mRNA expression of the two antiproteases. The impact of the systemic changes on lung antiprotease defense was evaluated by measuring levels and bioactivity of antiproteases in broncho-alveolar lavage fluid (BALF). Markers of alveolar-capillary barrier derangement were also studied. Non-parametric ANOVA (Kruskall-Wallis) and linear regression analysis were used.

Results: Severe peribronchiolar injury involving edema, intra-alveolar proteinaceous debris, hemorrhage and PMNn cell infiltration was seen in the first $24 \mathrm{~h}$ and later resolved. Despite a large increase in several lung cytokines, only IL-6 was found elevated in blood, preceding increased liver expression and blood concentration of both antiproteases. These changes, with an acute phase response profile, were significantly larger for alpha2-macroglobulin (40-fold increment in expression with 12-fold elevation in blood protein concentration) than for alpha1-antitrypsin (2-3 fold increment in expression with 0.5 -fold elevation in blood protein concentration). Both the increment in capillary-alveolar antiprotease concentration gradient due to increased antiprotease liver synthesis and a timely-associated derangement of the alveolar-capillary barrier induced by aspiration, contributed a 58-fold and a 190-fold increase in BALF alpha1-antitrypsin and alpha2-macroglobulin levels respectively $(p<0.001)$.

(Continued on next page)
\end{abstract}

\footnotetext{
* Correspondence: gborzone@med.puc.cl

'Department of Respiratory Diseases and Medical Research Center, Faculty of

Medicine, Pontificia Universidad Católica de Chile, Marcoleta 350, piso 1,

Santiago, Chile

Full list of author information is available at the end of the article
} 
(Continued from previous page)

Conclusions: Gastric contents-induced acute lung injury elicits a liver acute phase response characterized by increased mRNA expression of antiproteases and elevation of blood antiprotease concentrations. Hepatic changes act in concert with derangement of the alveolar capillary barrier to enrich alveolar spaces with antiproteases. These findings may have significant implications decreasing protease burden, limiting injury in this and other models of acute lung injury and likely, in recurrent aspiration.

Keywords: Aspiration, Liver acute phase response, Acute phase proteins, a1-antitrypsin, a2-macroglobulin, Alveolar-capillary barrier, Lung antiprotease defense

\section{Background}

Gastric contents aspiration is defined as the inhalation of gastric material into the airways below the level of the vocal cords, with consequences that are variable, ranging from an almost asymptomatic episode to severe acute lung injury (ALI) with high mortality $[1,2]$. In fact, gastric contents aspiration is a major direct cause of ALI. Although the true incidence of aspiration-induced lung injury is difficult to estimate considering that many aspiration events are silent, trauma and ICU patients with altered states of consciousness as well as patients requiring emergency anesthesia are at high risk of aspiration [2]. The deleterious effects of aspiration also depend on the terrain in which it occurs, as recently shown by Tsai et al., who found that aspiration of gastro-esophageal reflux increases the risk of intensive care unit admission and mechanical ventilation use among patients with chronic obstructive pulmonary disease [3].

The initial local lung effects of aspiration have been extensively studied in animal models [2, 4-15]. These effects include severe derangement of the alveolar capillary barrier with extravasation of plasma constituents from the vascular to the alveolar spaces, polymorphonuclear neutrophil recruitment and expression of proinflammatory mediators. Recently, we contributed to the understanding of resolution of the initial ALI induced by whole gastric juice in a rat model [5], showing that resolution involves an organizing pneumonia with granuloma formation, that later resolves.

However, very little is known about effects outside of the lung that are likely to occur in association with local lung effects and that may have important implications in the course of ALI and its prognosis.

Stimulated by a complex intercellular signaling system involving pro-inflammatory cytokines, the liver responds to inflammation localized in distant organs, with the acute phase response (APR) [16], a response that has been studied in rodents with a variety of stimuli such as LPS, turpentine administration and exposition to thermal injury [17, 18], all stimuli that do not affect the lung primarily. This response is characterized by significant changes in blood levels of acute phase proteins (APPs), such as C-reactive protein, clotting and complement proteins and proteinase inhibitors [16].

Very limited studies have investigated the APR in relation to inflammatory processes affecting the lung primarily $[19,20]$ but interestingly, these studies have not evaluated whether or not liver-synthesized lung antiproteases are involved.

We hypothesized that aspiration-induced lung inflammation elicits a hepatic APR. We also hypothesized that increased blood levels of antiproteases will be part of this response and will contribute to increase bronchoalveolar lavage fluid (BALF) levels of antiproteases.

The aim of our work was to investigate whether and to what extent aspiration of gastric fluid induces a hepatic acute phase response in a rat model of orotracheal instillation of whole gastric fluid, and if so, to determine the effects of this response on lung antiprotease levels. This model has been well characterized by our group according to ATS recommendations [21], and meets all the requirements for a model of ALI with severe histological and physiological changes, which resolve leaving normal lung architecture [5].

We found that the severe lung inflammatory reaction induced by orotracheal instillation of whole gastric fluid elicits significant systemic effects that result in upregulation of important lung antiproteases, contributing to improve lung antiprotease defences, underscoring an important role of the liver promoting lung tissue protection in acute lung injury. We believe that understanding how the liver response integrates with the local lung inflammatory response to promote immunity and tissue protection during aspiration of gastric contents will help to identify new approaches to treat this condition.

\section{Methods}

\section{Animal model of orotracheal instillation of rat whole gastric fluid}

The study was performed according to a protocol submitted to and approved by the Animal Research Ethics Committee of the Pontificia Universidad Católica de Chile. 


\section{Gastric fluid pool}

Gastric fluid was obtained through a gastrotomy from adult male Sprague-Dawley rats $(300 \pm 10 \mathrm{~g})$ fasted overnight and anesthetized intra-peritoneally with xylazineketamine (5.1 and $55.1 \mathrm{mg} \mathrm{x} \mathrm{kg}{ }^{-1}$, respectively). Gastric fluid samples were pooled, filtered through a $100 \mu \mathrm{m}$ mesh filter and kept at $-80{ }^{\circ} \mathrm{C}$. Animals were euthanized thereafter by exsanguination under anesthesia.

\section{Orotracheal instillation}

Under the same anesthetic protocol, another set of animals was orotracheally intubated with a $22 \mathrm{G}$ wire-fed catheter. Visualization of the glottis was achieved using a modified human otoscope (Welch Allyn ${ }^{\circ}$ ). A volume of gastric fluid $\left(1.5 \mathrm{ml} \mathrm{x} \mathrm{kg}{ }^{-1}, \mathrm{pH}=1.69\right)$ previously found by us to distribute evenly (data not shown) was instilled and animals allowed to recover spontaneously from anesthesia.

\section{Study groups}

Animals were studied at 4, 12, $24 \mathrm{~h}$, and at days 4 and 7 after instillation ( $n=10$ per group). Animals without intervention served as controls $(n=10)$.

\section{Sample collection}

Blood samples from the vena cava and snap frozen liver samples were obtained through a laparotomy prior to opening the thorax. Lungs were excised en bloc and the left main bronchus cannulated for bronchoalveolar lavage. For each animal, three aliquots of $0.15 \mathrm{M}$ saline ( $1 \mathrm{ml}$ each) were instilled, immediately aspirated, pooled and stored at $-80{ }^{\circ} \mathrm{C}$. BALF percent recovery was $67 \pm$ $7 \%$. The right middle lobe was excised to prepare $10 \%$ tissue homogenates in phosphate buffer. The caudate lobe was used to obtain the wet-to-dry weight ratio. The right lower lobe was fixed at $20 \mathrm{~cm} \mathrm{H}_{2} \mathrm{O}$ with $10 \%$ buffered formaldehyde solution and paraffin-embedded for histologic studies. The right upper lobe was excised and frozen for biochemical and molecular analysis.

\section{Histologic evaluation}

For each animal, four whole lobe longitudinal sections $(5 \mu \mathrm{m})$ were obtained and stained with hematoxylineosin for analysis by light microscopy as in [5], following ATS recommendations [21].

\section{Markers of alveolar-capillary barrier derangement}

a) Total protein concentration in BALF was measured using the Bradford protein assay [22].

b) Lung wet-to-dry weight ratio: The caudate lobe was removed and weighed immediately. After desiccation at $60{ }^{\circ} \mathrm{C}$ the lobe was weighed again to determine its wet-to-dry weight ratio. c) In a new set of animals ( $n=5$ per group), the Evans blue dye was utilized as a marker for derangement of the alveolar-capillary barrier [23]. Four hours prior to sacrifice, the Evans blue dye was injected via tail vein and its extravasation into BALF was quantified by spectrophotometry (Shimadzu, Japan).

\section{Levels of pro-inflammatory cytokines and IL-10}

Serum, BALF and lung tissue homogenate levels of IL-6, IL- $1 \beta$, TNF- $\alpha$ and IL-10 were measured in duplicate with commercially available enzyme-linked immunosorbent (ELISA) assay kits (Quantikine, R\&D Systems, USA) according to the manufacturer's instructions. Microplates were read using a microplate reader (BIOTEK $^{\bullet}$ Instruments, INC. Winooski, Vermont, USA).

\section{Levels of blood and BALF acute phase proteins}

Changes in the level of three acute phase proteins were studied in plasma: fibrinogen, $\alpha 1-\mathrm{AT}$ and $\alpha 2-\mathrm{MG}$, whereas changes in $\alpha 1-\mathrm{AT}$ and $\alpha 2-\mathrm{MG}$ were studied in BALF.

a) Fibrinogen: Plasma fibrinogen levels were determined by the Von Clauss coagulation micro-method [24]. b) $\alpha 1-A T$ : Both abundance and bioactivity of this antiprotease were measured in plasma and BALF:

- Western blot analysis of $\alpha 1-A T: 30 \mu \mathrm{g}$ of plasma or BALF proteins were separated by $10 \%$ SDS-PAGE and immobilized onto $\mathrm{NO}_{2}$-cellulose membranes (0.45 $\mu \mathrm{m}$ pore; Thermo Scientific, Rockford, IL, USA). Membranes were probed with an anti-human $\alpha 1-A T$ rabbit antibody (Sigma, Mississauga, ON, Canada) and then with a goat anti-rabbit peroxidaseconjugated antibody (Thermo Scientific, Rockford, IL, USA). $\alpha 1-A T$ immunoreactivity was visualized by enhanced chemiluminescence (SuperSignal ${ }^{\circ}$ Pico Chemiluminescent Substrate kit; Thermo Scientific, Rockford, IL, USA) and Kodak X-ray film. Densitometric analysis was performed using the Image J 5 Program. Equal loading was controlled by Ponceau staining.

- $\alpha 1-A T$ bioactivity measured by the Elastase Inhibitory Capacity (EIC) colorimetric assay: The inhibition that plasma and BALF samples exerted on the in vitro elastase-induced N-succinyl-Ala-Ala-Ala-p-nitroanilide (SLAPN; Sigma) hydrolysis test was studied [25, 26]. The rate of p-nitroanilide released at $25^{\circ} \mathrm{C}$ was followed for $3.5 \mathrm{~min}$ at $405 \mathrm{~nm}$ wavelength using a microplate spectrophotometer reader (BIO-TEK ${ }^{\circ}$ Instruments, Inc. Winooski, Vermont, USA). Serial dilutions were assayed in order to calculate the volume of plasma and BALF needed to produce $50 \%$ inhibition of the in vitro elastase activity. Results were expressed as 1 /dilution required for $50 \%$ inhibition. 
c) $\alpha 2$-macroglobulin: Plasma and BALF levels were measured by ELISA (Abcam Inc. Cambridge, MA, USA) according to the manufacturer's instructions. Microplates were read using a microplate reader (BIO-TEK ${ }^{\circ}$ Instruments, INC. Winooski, Vermont, USA).

\section{mRNA expression of a1-AT and a2-MG in liver samples}

a) RNA extraction and reverse transcription: Total RNA was isolated from snap frozen liver samples using Total RNA Mini Kit Tissue (Geneaid Biotech Ltd., Taiwan) according to the manufacturer's instructions and $2 \mu \mathrm{g}$ of total RNA of each sample was treated with DNAse I (Amplification grade; Invitrogen, USA). The single-strand cDNA was synthesized using Superscript II Reverse transcriptase (Invitrogen, USA) in $20 \mu$ total volume with Random Primer (Invitrogen, USA) according to manufacturer's instructions.

b) Semiquantitative Real-Time RT-PCR: The 7500 Fast Real-Time PCR System (Applied Biosystems) was used to quantify the relative gene expression of $\alpha 1$-AT and $\alpha 2-M G$ in rat liver; GAPDH was chosen as the housekeeping gene. PCR was performed using sequence-specific primers for $\alpha 1-\mathrm{AT}, \alpha 2-\mathrm{MG}$ and GAPDH (Table 1) in a reaction mix containing Fast SYBR Green PCR Master Mix (Invitrogen, USA). All real-time PCR assays were performed in duplicate.

The thermal cycling conditions included an initial activation step at $95{ }^{\circ} \mathrm{C}$ for $20 \mathrm{~s}$, followed by 40 cycles at $95{ }^{\circ} \mathrm{C}$ for $3 \mathrm{~s}$ and $60{ }^{\circ} \mathrm{C}$ for $30 \mathrm{~s}$ with an ultimate melting cycle $\left(95-60{ }^{\circ} \mathrm{C}\right)$. The annealing condition for GAPDH was $66{ }^{\circ} \mathrm{C}$ for $30 \mathrm{~s}$. In order to verify the specificity of each product, amplified products were subjected to melting curve analysis as well as to electrophoresis.

Relative real-time RT-PCR quantitation was performed according to Livak and Schmittgen [27], using the comparative threshold cycle $\left(\mathrm{C}_{\mathrm{T}}\right)$ values [28]. The DeltaDelta $C_{\mathrm{T}}\left(\Delta \Delta \mathrm{C}_{\mathrm{T}}\right)$ was calculated according to Eq. 1:

Table 1 Primer sequences for RT-PCR and product sizes

\begin{tabular}{lll}
\hline Gene name & Primer sequence & $\begin{array}{l}\text { Product } \\
\text { size }\end{array}$ \\
\hline a1-AT & $\begin{array}{l}\text { sense: 5' - cca cgg tga agg tgc cca tga tga-3' } \\
\text { antisense: 5' - tca gca cag cct tat gca cag cct-3' }\end{array}$ & 375 bp \\
a2-MG & sense:5'-atc tac atg gtg atg gtt cc-3' & 209 bp \\
& antisense:5'- acc tca ttg gat gaa gac tg-3' & \\
GAPDH & sense: 5'-acc aca gtc cat gcc atc ac -3' & 451 bp \\
& antisense: 5'-tcc acc acc ctg ttg ctg ta -3' & \\
\hline
\end{tabular}

$$
\Delta \Delta C_{\mathrm{T}}=\left(\mathrm{C}_{\mathrm{T}, \text { Target }}{ }^{-} \mathrm{C}_{\mathrm{T}, \mathrm{GAPDH}}\right)_{\text {timeX }}-\left(\mathrm{C}_{\mathrm{T}, \text { Target }}{ }^{-} \mathrm{C}_{\mathrm{T}, \mathrm{GAPDH}}\right)_{\text {time } 0}
$$

where, $\left(\mathrm{C}_{\mathrm{T} \text {,Target }}-\mathrm{C}_{\mathrm{T}, \mathrm{GAPDH}}\right)$ time o represents normalized expression in controls, and $\left(\mathrm{C}_{\mathrm{T} \text {,Target }}-\mathrm{C}_{\mathrm{T}, \mathrm{GAPDH}}\right)_{\text {time } \mathrm{x}}$ is the normalized expression at the different time points of the study. The relative fold expression (RFE) of the target genes was calculated as in Eq. 2:

$$
\mathrm{RFE}=2^{-\Delta \Delta \mathrm{CT}}
$$

\section{Statistical analysis}

Non parametric analysis of variance (Kruskall-Wallis) and linear regression analysis were used [29]. Graph Pad Prism 5.0 software was utilized. A $p$ value $<0.05$ was considered statistically significant.

\section{Results}

Gastric fluid-induced acute lung injury and proinflammatory mediators

Histologic evaluation of the lung was performed at alltime points after instillation according to ATS recommendations [21]. Figure 1 shows results at several time points after instillation. At $4 \mathrm{~h}$, increased alveolar thickening by interstitial edema and inflammatory cell infiltration, along with abundant protein-rich intra-alveolar exudate containing neutrophils and red blood cells were seen, adopting a peribronchiolar distribution. These changes became more intense at 12 and $24 \mathrm{~h}$, with patchy consolidation due to coalescence of affected areas. At 4 and 7 days, foreign-body giant cells, either isolated or forming granulomas were frequently observed, along with intra-alveolar buds of granulation tissue. In the first 4 to $24 \mathrm{~h}$, there was a large increase in inflammatory cells (more than $80 \%$ PMNn cell predominance) whereas at days 4 and 7 , mononuclear cells predominated [5].

Markers of increased alveolar-capillary barrier permeability at different times after whole gastric fluid instillation are shown in Fig. 2 and Table 2. Using several markers of alveolar-capillary barrier permeability, the largest increase in permeability was seen at $4 \mathrm{~h}$. Figure 2 shows that at $4 \mathrm{~h}$ there was a large extravasation of the intravenous Evans blue dye into BALF with gradual return to control values at $12-24 \mathrm{~h}$, suggesting progressive restitution of barrier integrity. Non-significant changes in blood levels of Evans blue dye after IV injection were found. As seen in Table 2, lung wet-to-dry weight ratio showed a large but transient increase at $4 \mathrm{~h}(p<0.001)$ with return to control values at $12 \mathrm{~h}$. Table 2 also shows that BALF total protein concentration increased markedly (76 times the control value, $p<0.001$ ) at $4 \mathrm{~h}$ and, 


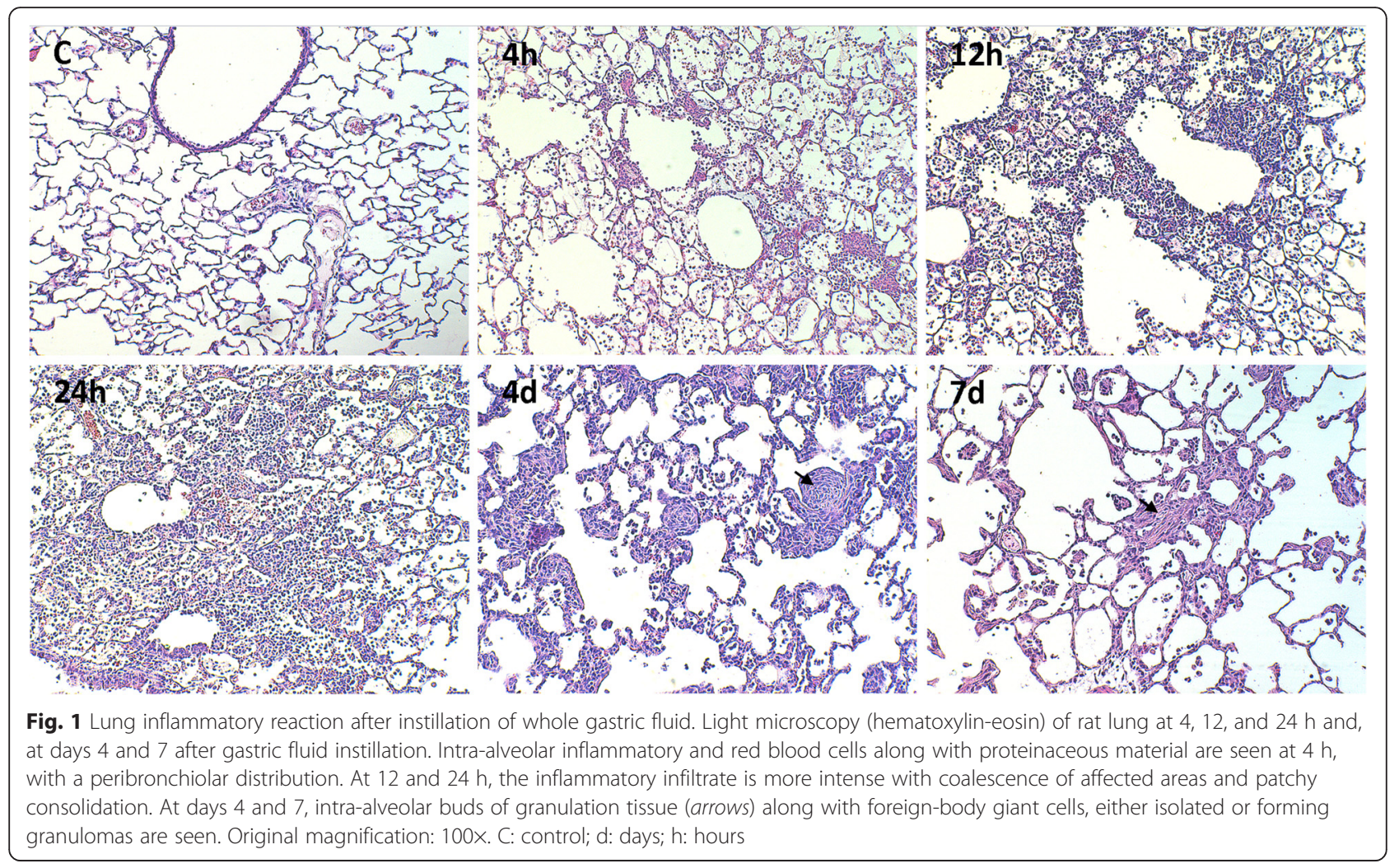

although at a significantly lower level, it remained elevated at 12 and $24 \mathrm{~h}(p<0.001)$.

Changes in cytokines in BALF and lung tissue homogenates at different times after instillation are illustrated in Fig. 3. Pro-inflammatory cytokines IL-6, IL-1 $\beta$ and TNF- $\alpha$ were non-detected in control BALF and all

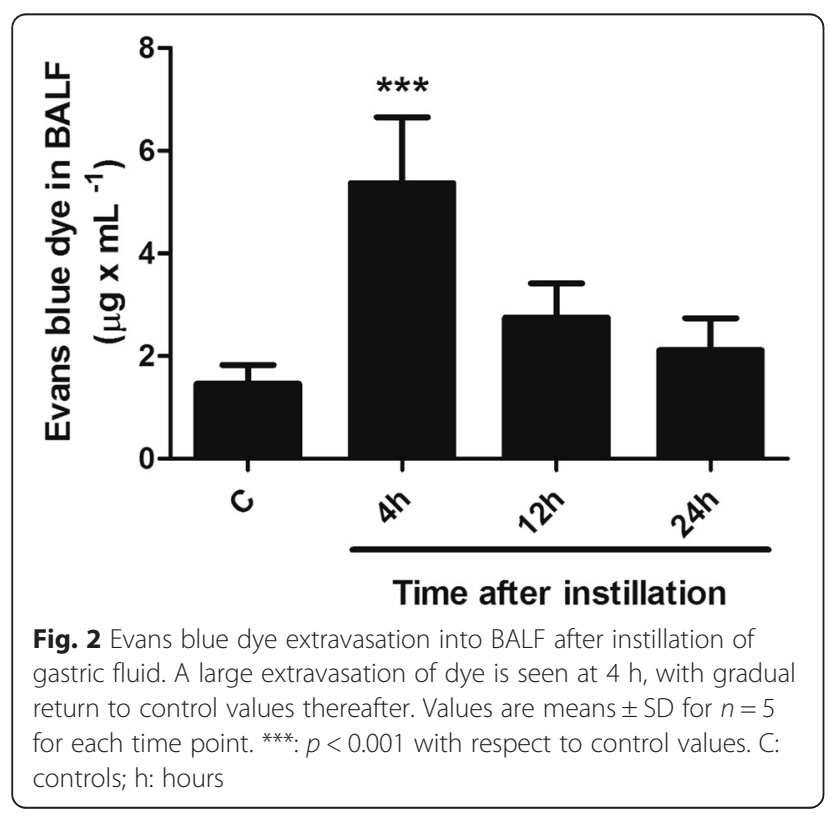

showed an early increase in concentration after instillation, being mild for TNF- $\alpha$ and very large for IL- 6 (Fig. 3a) and IL-1 $\beta$ (Fig. 3b). Whereas IL-6 increased mainly in BALF, IL-1 $\beta$ increased mainly in lung tissue homogenate, likely indicating differences in the cellular source of these cytokines. The highest levels of IL- 6 were seen at $4 \mathrm{~h}(8,400 \mathrm{pg} / \mathrm{ml}, p<0.001)$ with a progressive reduction later on. The highest levels of IL-1 $\beta$ were seen at $12 \mathrm{~h}(10,900 \mathrm{pg} / \mathrm{ml}, p<0.001)$ with a significant reduction at $24 \mathrm{~h}(p<0.01)$. Levels of TNF- $\alpha$ both in BALF and lung tissue homogenate showed a brief and moderate increase at $4 \mathrm{~h}(600 \mathrm{pg} / \mathrm{ml}, p<0.001)$, with significant reduction thereafter (Fig. 3c). On the other hand, IL-10 levels showed a progressive increase between 4 and $24 \mathrm{~h}(p<0.001)$ but only in BALF. In lung

Table 2 Markers of alveolar - capillary barrier derangement

\begin{tabular}{|c|c|c|c|c|c|}
\hline & Control & $4 \mathrm{~h}$ & $12 \mathrm{~h}$ & $24 \mathrm{~h}$ & $4 d$ \\
\hline \multicolumn{6}{|l|}{ Wet-to-dry weight ratio } \\
\hline Mean & 4,60 & $5,67 * * *$ & 4,71 & 4,56 & 4,80 \\
\hline S.D. & 0,10 & 1,01 & 0,21 & 0,11 & 0,24 \\
\hline \multicolumn{6}{|c|}{ BALF total protein content } \\
\hline Mean $\left(\mathrm{mg} \times \mathrm{mL}^{-1}\right)$ & 0,19 & $14,52 * * *$ & $10,78 * * *$ & $9,51 * * *$ & 0,88 \\
\hline S.D. & 0,1 & 7,1 & 5,46 & 4,04 & 0,39 \\
\hline
\end{tabular}

$h$ hours, $d$ days

$*_{* * *}: p<0,001$ with respect to control values 


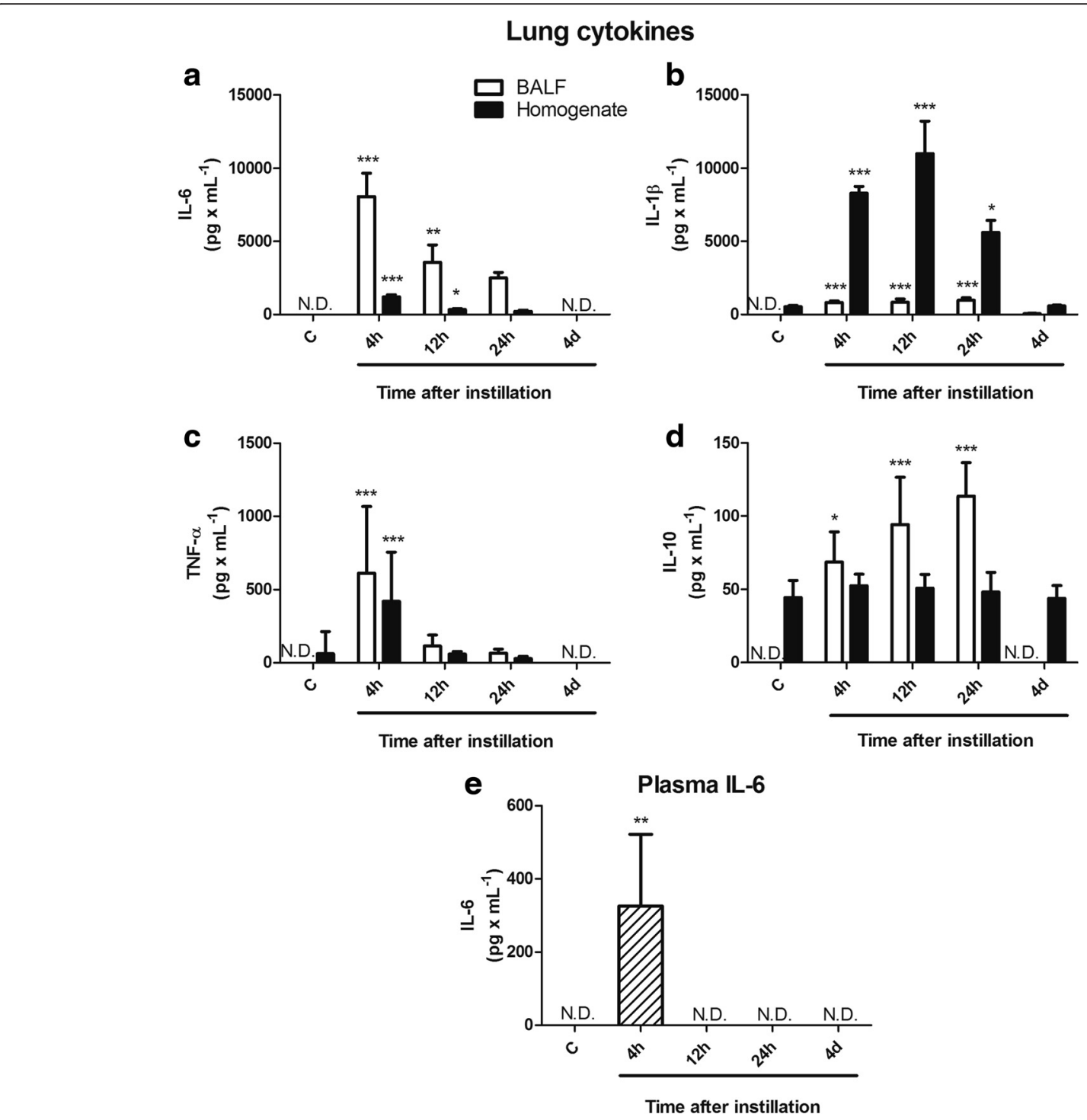

Fig. 3 Pro-inflammatory cytokines and IL-10 levels in BALF, lung tissue homogenate and blood after instillation. a In the lung, IL-6 levels increased mainly in BALF, with a peak at $4 \mathrm{~h}$ and a progressive reduction to become non detectable at $4 \mathrm{~d}$. $\mathbf{b} \mathrm{IL}-1 \beta$ levels increased mainly in lung tissue homogenate with a peak level at $12 \mathrm{~h}$ and a significant reduction thereafter. c Levels of TNF-a showed a brief and moderate increment at $4 \mathrm{~h}$ both in BALF and lung tissue homogenate, with a significant reduction thereafter. $\mathbf{d}$ IL-10 levels in BALF showed a progressive increase between $4 \mathrm{~h}$ and $24 \mathrm{~h}$ and became non detectable at $4 \mathrm{~d}$, without changes in lung tissue homogenate. e In spite of the high levels of pro-inflammatory cytokines observed in the lung, only IL-6 was detected in plasma at $4 \mathrm{~h}$ after instillation. Open bars correspond to cytokine levels in BALF, solid bars correspond to cytokine levels in lung tissue homogenate and the hatched bar corresponds to IL-6 levels in plasma. Results are means \pm SEM. *: $p<0.05 ;{ }^{* *}: p<0.01 ;{ }^{* * *}: p<0.001$ with respect to control values. C: controls; h: hours; d: days; N.D.: non detectable

tissue homogenates, IL-10 remained detectable but unchanged throughout (Fig. 3d).

Changes in all measured cytokines in both BALF and lung tissue were transient and all the cytokines studied reached control levels at day 4.

In spite of the high levels of pro-inflammatory cytokines produced in the lung after instillation of gastric fluid, only IL-6 was detected transiently in plasma at $4 \mathrm{~h}$ (Fig. 3e).

\section{Acute phase proteins in blood}

Changes in the levels of acute phase proteins in blood are shown in Figs. 4 and 5.

Fibrinogen concentration in plasma was not increased at $4 \mathrm{~h}$ but showed a mean increase of $68 \%$ at 12 and $24 \mathrm{~h}$ $(p<0.001)$, with return to control values at day 4 (Fig. $4 \mathrm{a})$.

a2-MG concentration in plasma was not increased at $4 \mathrm{~h}$ but showed a mean increase of 7.5 times above 


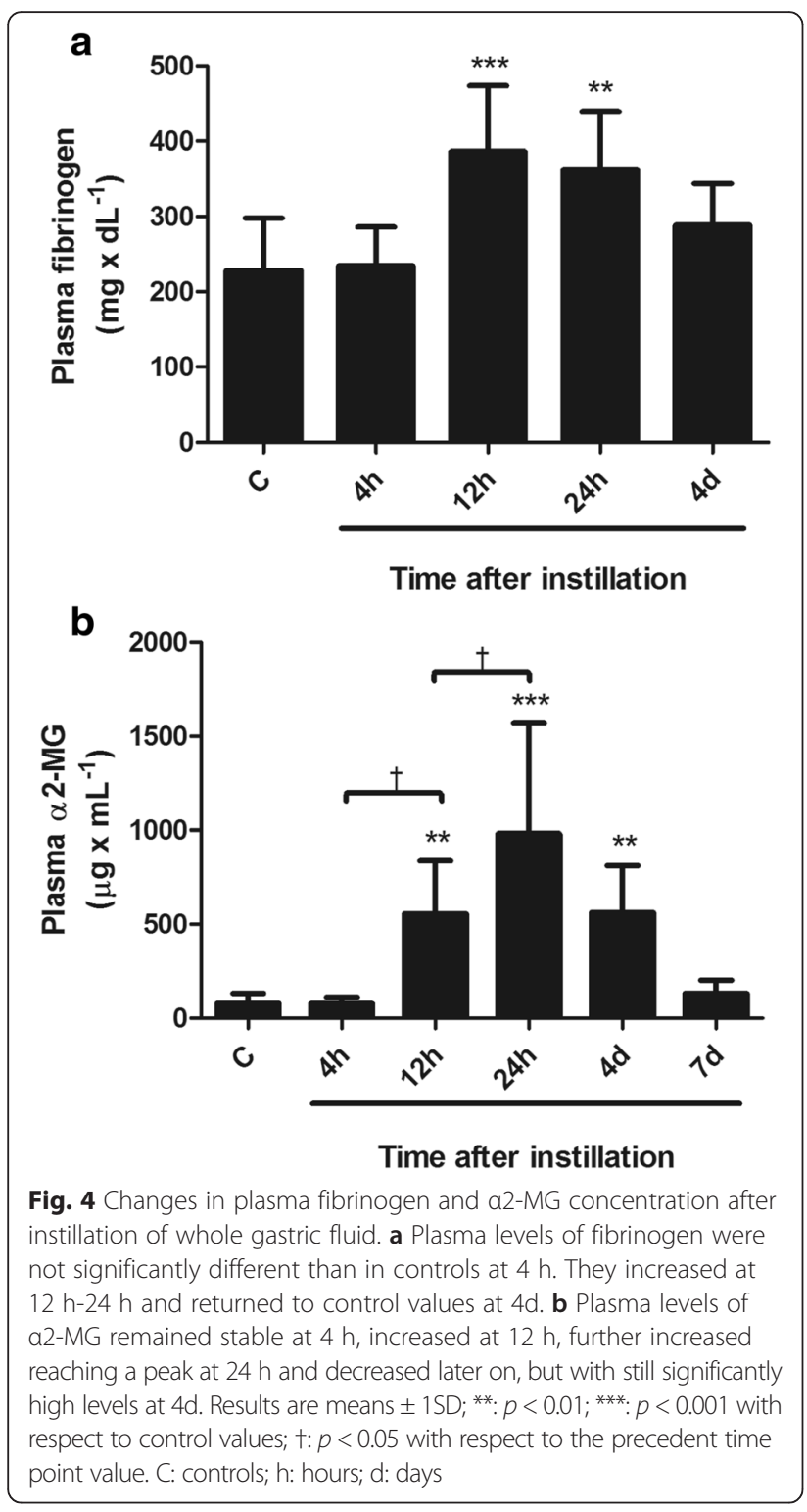

control values at $12 \mathrm{~h}(\mathrm{p}<0.01)$ and of 13.4 times at $24 \mathrm{~h}(\mathrm{p}<0.001)$, with significant reduction thereafter, to reach control values at day 7 (Fig. 4b).

a1-AT abundance and bioactivity in plasma after instillation of whole gastric fluid are shown in Fig. 5. Figure $5 \mathrm{a}$ illustrates changes in plasma $\alpha 1-\mathrm{AT}$ abundance in a representative Western blot. The $\sim 55 \mathrm{kDa} \alpha 1$-AT immunoreactive band that is seen in the control sample increases at $24 \mathrm{~h}$ after treatment and decreases at day 4 . Figure $5 \mathrm{~b}$ shows the results of the densitometric analysis of $\alpha 1$-AT Western blots, normalized by their corresponding Ponceaus and expressed as times over control values ( $n=4$ for each time point). $\alpha 1$-AT immunoreactivity increased 1.5 times at $24 \mathrm{~h}$ after instillation $(p<$ 0.01 ) and was back to control values at day 4 . Figure $5 \mathrm{c}$ shows that changes in plasma $\alpha 1-\mathrm{AT}$ bioactivity were similar to changes in immunoreactivity. At $24 \mathrm{~h}, \alpha 1-\mathrm{AT}$ bioactivity increased significantly (1.3 times the control values $(p<0.01))$, with return to control values at day 4 .

The time course of changes in blood concentration of these three acute phase proteins, preceded by elevation of IL-6 levels in blood, was compatible with a rodent acute phase response profile [17].

Gene expression of antiproteases a1-AT and a2-MG in the liver

In Fig. 6a, the two- to three-fold mean increase in $\alpha 1$ AT mRNA, that was seen at $4 \mathrm{~h}$ and persisted during the first $24 \mathrm{~h}$, did not reach statistical significance. Nevertheless, this change in expression preceded small but significant changes in $\alpha 1$-AT protein abundance and bioactivity in blood with a liver acute phase response profile.

Figure $6 \mathrm{~b}$ shows that changes in $\alpha 2-\mathrm{MG}$ mRNA expression were significantly larger than for $\alpha 1-A T$ mRNA expression, with a forty-fold mean increase at $4 \mathrm{~h}$, a 400 fold mean increase at $12 \mathrm{~h}(p<0.01)$ and a 900-fold mean increase at $24 \mathrm{~h}(p<0.05)$ and return to control values at day 4 . Changes in hepatic $\alpha 2-\mathrm{MG}$ mRNA expression preceded changes in blood $\alpha 2-\mathrm{MG}$ protein concentration.

Changes in lung antiprotease protection after instillation of gastric fluid

Figure 7 illustrates lung consequences of local and hepatic changes induced by instillation of whole gastric fluid on lung antiproteases $\alpha 1-\mathrm{AT}$ and $\alpha 2-\mathrm{MG}$.

\section{BALF a1-AT abundance by Western blot analysis}

Figure 7a shows a representative $\alpha 1$-AT Western blot of BALF samples. Control BALF shows two $\alpha 1$-AT immunoreactive bands in the $\sim 55-60 \mathrm{kDa}$ molecular size range, corresponding to the native $\alpha 1$-AT described in rodents [30]. After instillation, immunoreactivity of these bands increases and new bands are seen in the first 4-24 h: a $\sim 88 \mathrm{kDa}$ band corresponding to the [elastase- $\alpha 1-\mathrm{AT}$ ] complex [31] and a $\sim 45-50 \mathrm{kDa}$ band corresponding to the $\alpha 1$-AT proteolytic fragment, derived from the interaction between elastase and $\alpha 1-\mathrm{AT}[31,32]$. At day 4 , the immunoreactivity pattern of BALF $\alpha 1$-AT is similar to that in the control. Figure $7 \mathrm{~b}$ shows the densitometric analysis of Western blots for $\alpha 1$-AT ( $n=5$ for each time point), with a mean 4.2 fold increase in $\alpha 1$-AT immunoreactivity that is evident at $4 \mathrm{~h}$ and remains elevated up to $24 \mathrm{~h}$ after instillation $(p<0.001)$.

\section{BALF a1-AT bioactivity}

Figure $7 \mathrm{c}$ shows changes in BALF $\alpha 1$-AT bioactivity after instillation. A significant increase in bioactivity was seen at $4 \mathrm{~h}(p<0.001)$ with further increase later 


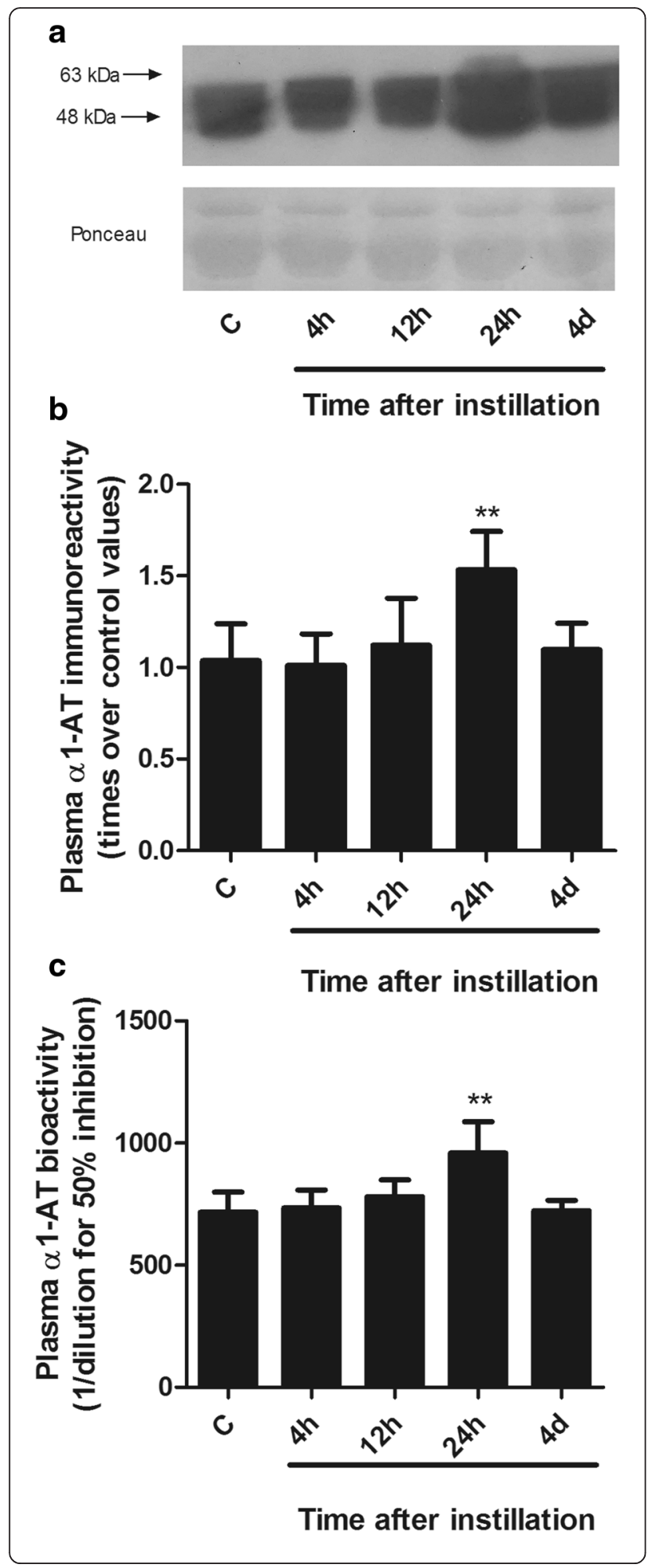

Fig. 5 Changes in plasma a1-AT abundance and bioactivity after instillation of whole gastric fluid. a Representative Western blot of plasma samples illustrating the time course of changes in plasma a1-AT abundance. The $\sim 55 \mathrm{kDa}$ a1-AT immunoreactive band seen in the control sample shows a significant enlargement at $24 \mathrm{~h}$. b Densitometric analysis of Western blots, normalized by their corresponding Ponceaus and expressed as times over control values ( $n=5$ for each time point). a1-AT immunoreactivity increased 1.5 times the control values at $24 \mathrm{~h}$ and was back to control levels at 4d. c Plasma a1-AT bioactivity increased 1.3 times with respect to control values at $24 \mathrm{~h}$ with return to control values at $4 \mathrm{~d}$. Bars are means $\pm 1 S D ;{ }^{* *}: p<0.01$ with respect to control values. C: controls; h: hours; d: days

on. At $24 \mathrm{~h} \alpha 1$-AT bioactivity was significantly higher than at $4 \mathrm{~h}(p<0.001)$ and returned to control level at day 4 .

\section{BALF a2-MG concentration}

Figure $7 \mathrm{~d}$ shows changes in $\alpha 2-\mathrm{MG}$ concentration. This high molecular weight protein was found in very low concentration in control BALF. A progressive increase in concentration was seen in the first $24 \mathrm{~h}(p<0.001)$, starting at $4 \mathrm{~h}$. A mean 51-fold increase in concentration at $4 \mathrm{~h}$ (that did not reach statistical significance), 105fold increase at $12 \mathrm{~h}$ and 194-fold increase at $24 \mathrm{~h}$ is shown, with return to control levels at day 4 , despite still increased levels of $\alpha 2-\mathrm{MG}$ in plasma.

\section{Two-phase response in antiprotease enrichment of the} alveolar spaces

As seen in Fig. 7, $\alpha 1$-AT bioactivity (7c) and $\alpha 2-\mathrm{MG}$ concentration (7d) in BALF at $4 \mathrm{~h}$ exhibit a similar large increment: a 40-fold and a 51-fold increase respectively in comparison to control values. These early changes in BALF occur without changes in blood levels of antiproteases as seen in Figs. 4b and 5. Instead, they occur in relation to the alveolar-capillary barrier derangement observed at $4 \mathrm{~h}$, as illustrated by Evans blue dye extravasation and the significant increase in BALF total protein content and in lung tissue wet to dry weight ratio.

After the first $4 \mathrm{~h}$, there is a further rise in the levels of both antiproteases in BALF, but with different slopes, as seen in Fig. 8. This figure summarizes the magnitude of changes in BALF antiproteases occurring in relation to their increased blood levels (as percent changes from values at $4 \mathrm{~h}$ ). An extra $18 \%$ increase in $\alpha 1$-AT bioactivity (Fig. 8a) and an extra $281 \%$ increase in $\alpha 2-M G$ concentration (Fig. 8b) were found in BALF. These BALF changes occur together with an increment in the levels of both antiproteases in blood (Figs. 4 and 5). During this period of time, there is no further derangement of the alveolar-capillary membrane. In fact, Evans blue dye extravasation returns to control values (Fig. 2), BALF total protein content decreases progressively up to $40 \%$ 


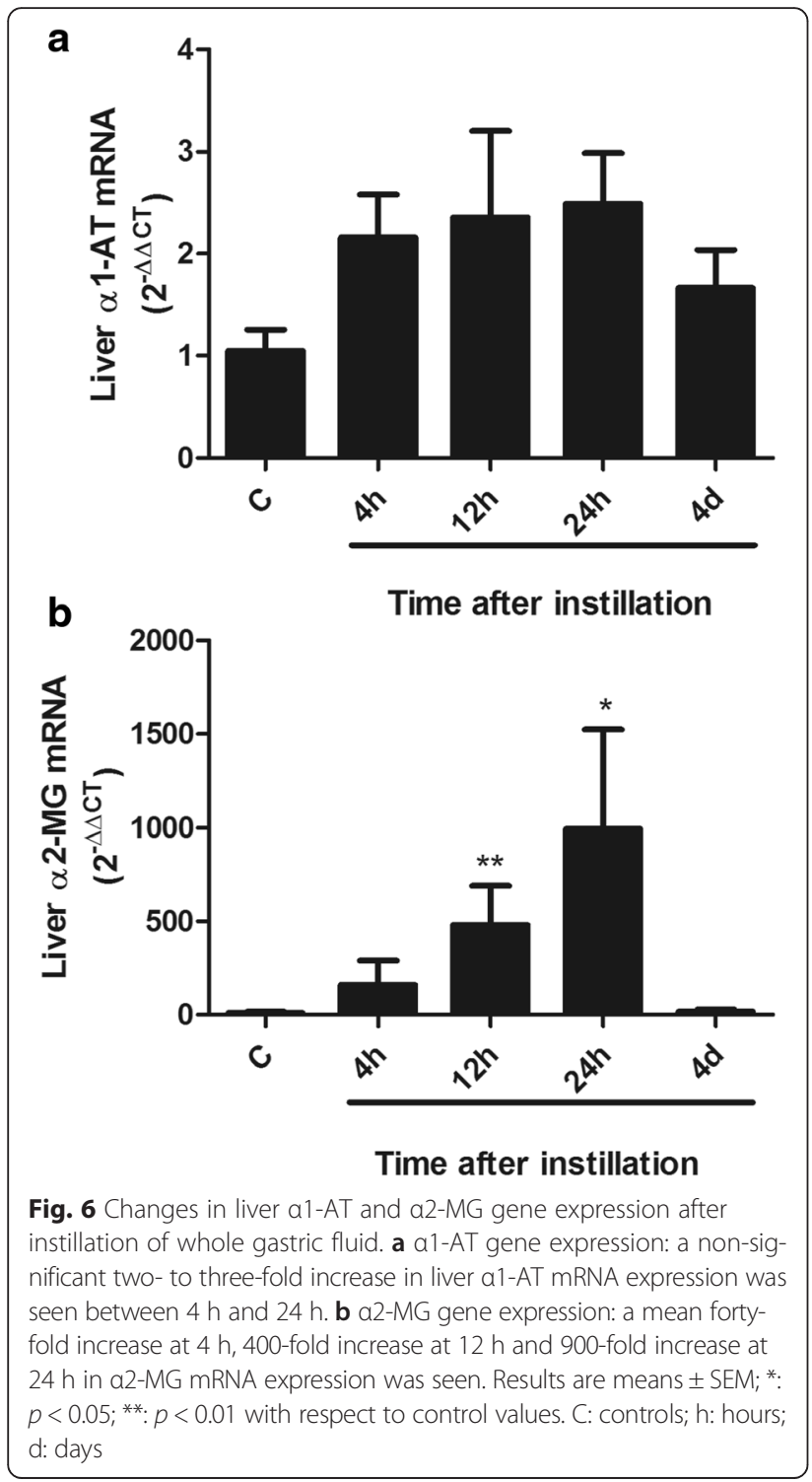

and wet to dry weight ratio reaches control values at $12 \mathrm{~h}$ (Table 2). Thus, during this period in which there is no further increase in permeability, antiprotease enrichment of the alveolar spaces likely occur in relation to the increment in the antiprotease capillary-alveolar concentration gradient, due to increased blood levels of antiproteases.

Figure 9 shows the effects of the two processes that occur in the first hours after instillation and that determine largely increased levels of $\alpha 2-\mathrm{MG}$ in BALF: a) the alveolar-capillary barrier derangement and b) the increase in blood concentration of $\alpha 2-M G$. In Fig. 9a, $\alpha 2-$ MG levels in BALF at $4 \mathrm{~h}$ do not correlate with $\alpha 2$-MG levels in blood, indicating that BALF levels of $\alpha 2-\mathrm{MG}$ are determined by derangement of the alveolar-capillary barrier that loses its protein size selectivity. In Fig. 9b, a significant positive correlation is seen between $\alpha 2$-MG levels in blood and $\alpha 2-$ MG levels in BALF at $12-24 \mathrm{~h}$. Data on plasma and BALF $\alpha 2-$ MG concentration fit a lineal regression of the form $y=0.0095 x+1.941 \quad(r=$ $0.64 ; p=0.028)$. In this time period, markers of increased alveolar capillary barrier permeability progressively decrease, indicating that BALF levels of $\alpha 2-\mathrm{MG}$ are determined by the APR that increases the $\alpha 2-\mathrm{MG}$ concentration gradient. In Fig. 9c, still elevated levels of $\alpha 2-$ MG in blood at day 4 do not result in elevated levels of $\alpha 2-\mathrm{MG}$ in BALF, reflecting restoration of the normal protein size selectivity of the alveolar-capillary barrier. Figure 9c also shows that at day 7, blood and BALF levels of $\alpha 2-\mathrm{MG}$ are back to control values.

\section{Discussion}

Our results show for the first time, that a severe lung inflammatory reaction induced by orotracheal instillation of whole gastric fluid elicits a liver acute phase response, with elevation of acute phase proteins in the blood stream. The main lung antiproteases are part of this response, since mRNA transcription of $\alpha 1-\mathrm{AT}$ and mainly of $\alpha 2-\mathrm{MG}$, is induced early in the liver, preceding elevation of the acute phase proteins in blood. Our results also show that the liver response contributes to the enrichment of the alveolar spaces with acute phase proteins that are important lung antiproteases. We identified a two-phase response in antiprotease enrichment of the alveolar spaces after aspiration, related to an early increase in alveolar-capillary barrier permeability and a later increment in capillary-alveolar antiprotease concentration gradient, due to increased blood concentration of antiproteases by increased liver synthesis.

\section{Biology of the acute phase response}

The systemic inflammatory response is a collection of coordinated physiologic changes initiated during early stages of inflammation as part of the early innate defense, triggered by a variety of stimuli with the goal of achieving homeostasis. A prominent feature of this response is synthesis of several proteins mainly by the liver, under the control of cytokines originating at the site of injury [16], referred to as the liver acute phase response (APR). Changes in blood during the hepatic APR have been studied in rodents in response to stimuli not affecting the lung primarily, such as LPS and turpentine administration and exposition to thermal injury, and a number of APPs have been shown to participate. With these stimuli, the rodent APR starts a few hours after the insult, reaches a peak $24-48 \mathrm{~h}$ later and is back to baseline values at day $7[17,18,33]$. In general, it is assumed that elevation of APPs in blood have beneficial effects based largely on the known function of each of the individual proteins involved and on logical speculations as to how these might be useful in inflammation 

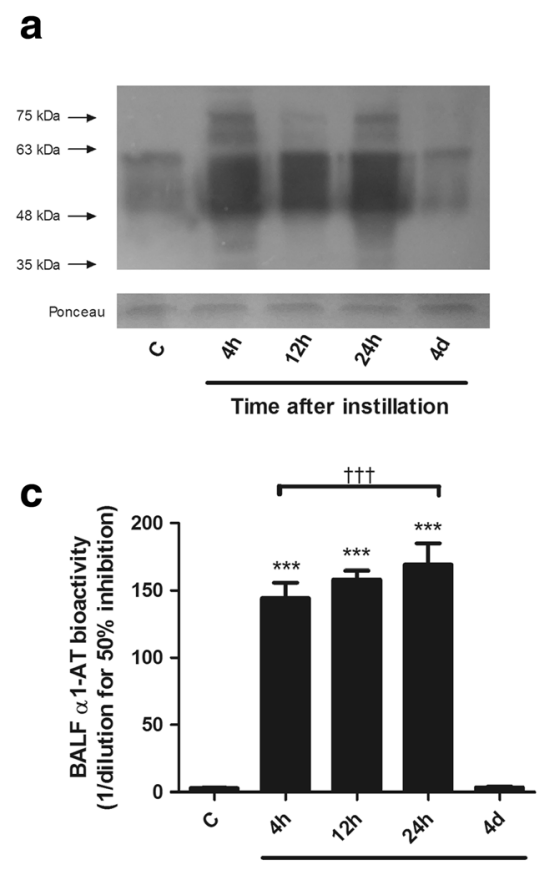

Time after instillation
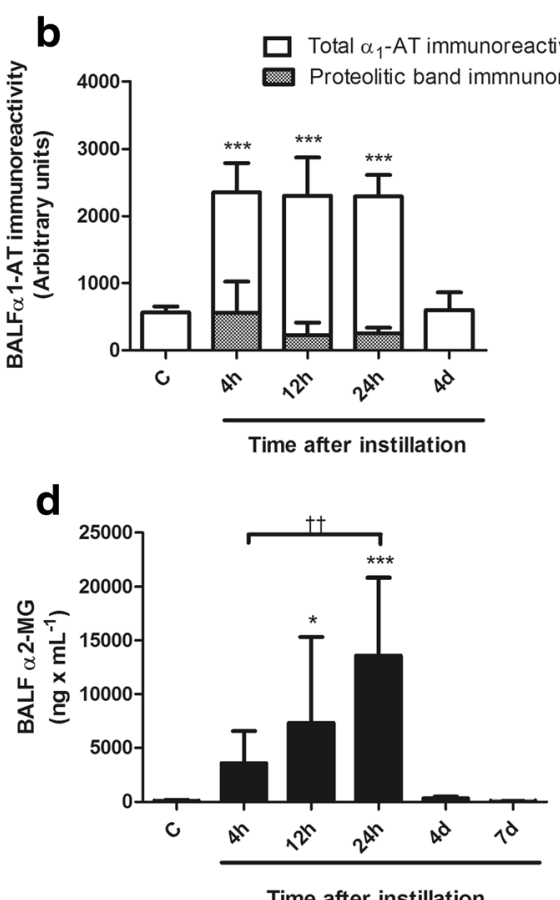

Fig. 7 Changes in a1-AT and a2-MG in BALF after instillation of whole gastric fluid. a Representative Western blot illustrating changes in BALF a1-AT immunoreactivity. Two bands in the $55-60 \mathrm{kDa}$, corresponding to the native antiprotease are seen. After instillation, an approximately 88-kDa band corresponding to the [a $a_{1}$-AT-elastase] complex and a 45-50 kDa band, corresponding to the proteolytic fragment derived from the interaction between $\mathrm{a}_{1}$-AT and elastase are present at $4 \mathrm{~h}, 12 \mathrm{~h}$ and $24 \mathrm{~h}$. In addition, the immunoreactivity of the 55-60 kDa band increases markedly at these time-points. Ponceau staining was used as a loading control. b Densitometric analysis of five independent Western blots. Total $\mathrm{a}_{1}$-AT immunoreactivity increased 4.2 times over control values at $4 \mathrm{~h}$, remained elevated up to $24 \mathrm{~h}$ and returned to control values at $4 \mathrm{~d}$. Proteolytic band immunoreactivity was present only between $4 \mathrm{~h}$ and $24 \mathrm{~h}$. Open bars correspond to the means \pm 1 SD of densitometric arbitrary units of total $a_{1}$-AT immunoreactivity. Hatched bars correspond to immunoreactivity of the $a_{1}$-AT proteolytic band. c Changes in $a_{1}$-AT bioactivity in BALF. Elastase inhibitory capacity increased 49 times over control values at $4 \mathrm{~h}$, with a further increase to 58 times the control values at $24 \mathrm{~h}$ and returned to control levels at day 4. $\mathbf{d}$ Changes in a2-MG concentration in BALF. a2-MG concentration increased significantly at $12 \mathrm{~h}$, with a peak at $24 \mathrm{~h}$. At $4 \mathrm{~d}$, a2-MG concentration was back to control values. Results are means \pm 1SD; *: $p<0.05 ;{ }^{* * *}: p<0.001$ with respect to control values; †t: $p<0.01 ; \dagger+t: p<0.001$ with respect to $4 \mathrm{~h}$. C: controls; h: hours; d: days
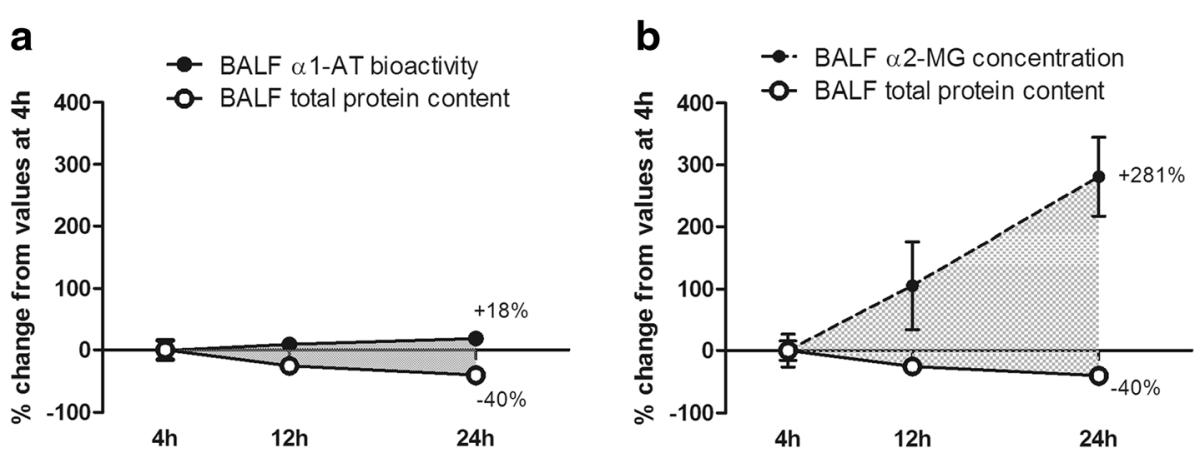

Fig. 8 BALF antiprotease enrichment after the first $4 \mathrm{~h}$, due to increased capillary-alveolar concentration gradient without further increase in permeability. a Changes in BALF a1-AT bioactivity and BALF total protein content between $4 \mathrm{~h}$ and $24 \mathrm{~h}$ after instillation. At $24 \mathrm{~h}$, while total protein content falls $40 \%$, BALF a1-AT bioactivity increases $18 \%$ above values observed at $4 \mathrm{~h}$. b Changes in BALF a2-MG concentration and BALF total protein content between $4 \mathrm{~h}$ and $24 \mathrm{~h}$ after instillation. At $24 \mathrm{~h}$, while total protein content falls $40 \%$, BALF a2-MG concentration increases $281 \%$ above values observed at $4 \mathrm{~h}$. h: hours 

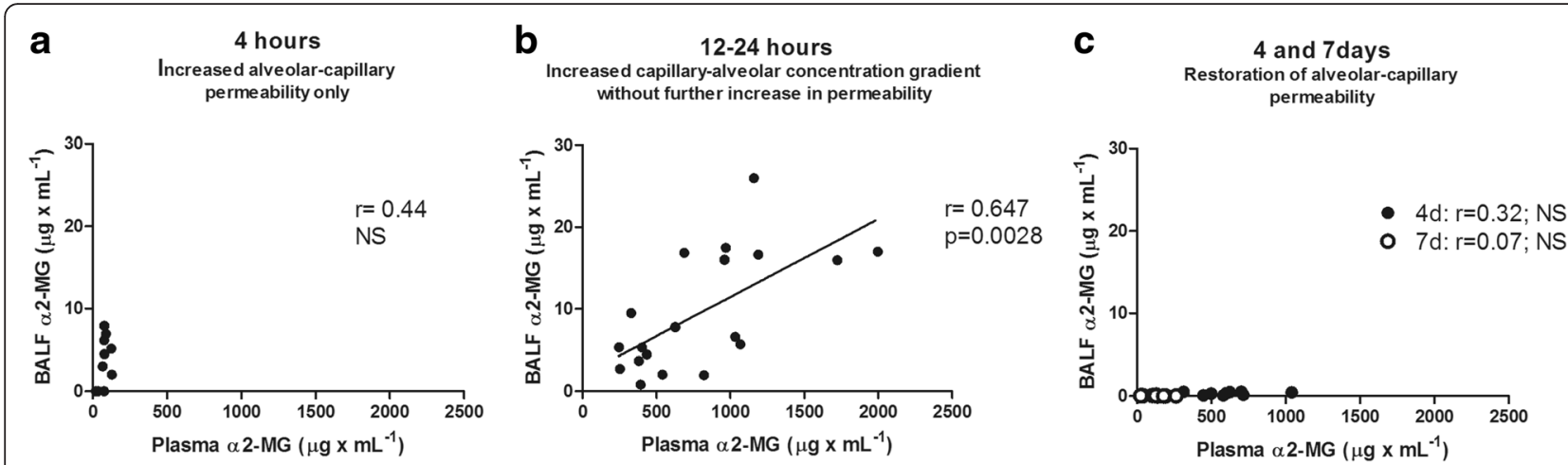

Fig. 9 Relationship between plasma and BALF a2-MG concentrations.a Relationship between plasma and BALF a2-MG concentration at 4 h. Lack of correlation ( $r=0.44$; p N.S.) between plasma and BALF levels of a2-MG is seen. Increased BALF a2-MG concentration without an increase in plasma a2-MG concentration indicates loss of the protein size selectivity of the alveolar-capillary barrier. $\mathbf{b}$ Relationship between plasma and BALF a2-MG concentration at 12-24 h. A significant positive correlation ( $r=0.647 ; p=0.0028)$ between plasma and BALF levels of a2-MG at 12-24 $\mathrm{h}$ is seen, indicating that BALF levels of a2-MG during this period are determined by the increase in a2-MG capillary-alveolar concentration gradient, due to the liver acute phase response. c Relationship between plasma and BALF a2-MG concentration at 4 and 7d. Still elevated levels of a2-MG in blood at 4d (solid circles) do not result in elevated levels of a2-MG in BALF, reflecting restoration of the normal protein size selectivity of the alveolar-capillary barrier. At 7d (open circles), blood and BALF levels of a2-MG are back to control values. h: hours; d: days

[16]. However, in the last few years, some negative implications of the hepatic APR have also been proposed, since the increase in blood of proteins with procoagulant effects such as fibrinogen, in relation to lung inflammation induced by urban air pollution and cigarette smoking, has been implicated in adverse cardiovascular effects [34]. In addition, this response has been implicated in the progression of lung damage in patients with COPD [35]. Unfortunately, studies relating cardiovascular morbidity and mortality during episodes of increased air pollution have focused only on Creactive protein and APPs with pro-coagulant effects and have not evaluated the full spectrum of proteins that are known to be co-expressed, among them several antiproteases that can reach the lung improving its defense properties.

\section{Acute phase response elicited by gastric fluid-induced lung inflammation}

Although the innate immune response to gastric contents aspiration has been extensively studied in the local lung environment, we have very little insights into extrapulmonary effects elicited by aspiration that could have implications modifying lung inflammation and the prognosis of a single aspiration event. As a matter of fact, there is little information on the cascade of cytokines released in the lung during aspiration-induced ALI that could induce an APR $[2,5]$. It has been proposed that the pattern of APPs produced in response to an injury and the cytokines involved in their regulation depends on the nature of the inflammatory stimulus [36]. Although it is known that IL-6, IL-1 $\beta$ and TNF- $\alpha$ modulate the synthesis of APPs in adult human hepatocytes, IL-6 is the major cytokine involved in the synthesis of the full spectrum of APPs [16, 33, 37]. IL-6 responsive regulatory elements have been found in the $\alpha 1$-AT gene that are responsible for both basal and induced expression of $\alpha 1-\mathrm{AT}$ in different human cell types and in rat hepatocytes [33, 38, 39]. On the other hand, it has been shown that IL-6 defective mice have a severely compromised APR to turpentine-induced tissue damage, as well as an impaired response following LPS injection $[40,41]$ and bacterial pneumonia [19]. In our model, IL-6 may play a role in the APR, since it was the only pro-inflammatory cytokine found to have increased levels in blood preceding changes in APPs, despite very high levels of other pro-inflammatory cytokines in the lung. It is also possible however, that other regulators could be involved in our model, since for instance in rats, CINC-1 the counterpart of human IL-8, has also been involved in APP production [42]. In our study, the high levels of IL-6 and TNF- $\alpha$ observed in BALF in comparison with lung tissue homogenate suggest that epithelial and alveolar mononuclear resident cells might be the source of these cytokines. In this regard, Fujii et al. have shown that the interaction between macrophages and epithelial cells has a synergistic effect on the production and release of mediators involved in the systemic inflammatory response [43]. With regard to the cytokine IL-10, we found that its concentration in BALF increases at the time proinflammatory cytokine levels decrease, in agreement with the known role of IL-10 limiting the cascade of pro inflammatory cytokines in lung inflammation [44].

In the literature, there is no information on the type and kinetics of APP production during gastric juiceinduced ALI. We found a significant increase in the three APPs studied, with a time course of a rodent APR $[17,18,33]$. Additionally, the increment in $\alpha 1$-AT 
concentration in blood was associated with a proportional increase in its activity. The increment in blood levels of $\alpha 1$-AT and $\alpha 2-$ MG was preceded by an increase in their mRNA expression in the liver, with the largest increase being that of $\alpha 2-\mathrm{MG}$, which is considered to be the main acute phase antiprotease in the rat [17]. As a matter of fact, $\alpha 1-\mathrm{AT}, \alpha 2-\mathrm{MG}$ and fibrinogen belong to the same group of APPs [16], responding to the same type of signal, involving activation of intracellular tyrosine kinase JAK and the acute-phase responsive factor, now called STAT3 [36, 45, 54].

On the basis of timing and magnitude of the changes observed in our model, we speculate that the increase in liver synthesis of fibrinogen, $\alpha 1-\mathrm{AT}$ and $\alpha 2-\mathrm{MG}$ could be mediated by the IL- 6 signaling, that is known to participate in activation of the JAK/STAT3 cascade. Future studies using IL-6 inhibition are warranted to further evaluate the role of this cytokine in gastric juice-induced APR.

Although $\alpha 1-\mathrm{AT}$ is the main lung antiprotease in steady-state conditions, exhibiting a broad range of antiinflammatory and immunoregulatory activities [37, 46], it is not the main acute phase antiprotease in the rat. It is produced primarily by the liver, with additional sources such as peripheral blood monocytes and alveolar macrophages contributing with a small fraction to total synthesis. Literature shows that similar to the liver, these additional sources are also known to respond to inflammatory stimuli with a small local APR, but their contribution to the increment in capillary-alveolar concentration gradient and to BALF APP levels is small $[19,47]$.

It has been shown that $\alpha 1-\mathrm{AT}$ is produced as part of the liver APR after turpentine injection in guinea pigs [48] and rats [17]. Support for a beneficial effect of $\alpha 1-$ AT as part of the APR is provided by a study in a rat model of renal ischemia-reperfusion injury, in which the administration of $\alpha 1-\mathrm{AT}$, at a dose that results in plasma levels similar to those observed during an APR, reduces inflammation, apoptotic activity and tissue damage [49]. Interestingly, we found complex formation between $\alpha 1$ AT and elastase in BALF between 4 and $24 \mathrm{~h}$ after instillation, providing evidence of the functionality of this antiprotease in our model.

With regard to $\alpha 2-\mathrm{MG}$, it inhibits different types of proteases and is also a carrier and regulator of the function of several cytokines. Its large size prevents it from diffusing easily through the normal alveolar-capillary barrier and thus, it is found in very low concentration in normal alveolar spaces $[46,50]$. It reaches the alveolar spaces in significant amounts whenever there is alveolarcapillary barrier derangement. Its role as a marker of alveolar-capillary barrier permeability has been studied in human acute respiratory distress syndrome [47]. In this condition, $\alpha 2-\mathrm{MG}$ has been found forming complexes with proteases and IL-8 [51]. Very little is known about its role as an acute phase protein in humans, however, it is recognized as the main acute phase antiprotease in the rat [17].

\section{Impact of the hepatic APR on lung antiprotease defense}

Containing the lung inflammatory response induced by gastric juice is critically important in order to inhibit progression to a persistent systemic inflammatory response fueled by persistently increased cytokine production. In this regard, liver-newly synthetized antiproteases reaching the alveolar spaces may play an important role limiting lung inflammation. It has recently been shown that the APR has a role improving animal survival in experimental bacterial pneumonia $[19,52,53]$ and although in these studies antiproteases were not evaluated, other APPs that were increased in blood were found increased in BALF [19]. On the other hand, research using APR-null mice in pneumonia has shown that in the absence of an APR, APPs do not increase in BALF and there is increased animal mortality [19, 54, 55]. Our results showed a highly significant enrichment in antiprotease content of the alveolar spaces, with a mean 58-fold increase in $\alpha 1$-AT activity and a mean 192-fold increase in $\alpha 2-$ MG concentration in BALF. Given the fact that in our model, the acidic component of gastric contents triggers an early derangement of the alveolar-capillary barrier that precedes in several hours the increment in blood APP concentrations, we were able to show a two-phase response in the enrichment of the alveolar spaces with antiproteases.

\section{Two-phase response in the enrichment of the alveolar spaces with antiproteases}

The first phase is characterized by an early and large increment in BALF antiprotease concentration and occurs prior to APP elevation in blood, thus not due to the APR, and instead due to derangement of the alveolar capillary barrier that loses its protein size selectivity, facilitating the passage of both small ( $\alpha 1-\mathrm{AT})$ and large ( $\alpha 2-\mathrm{MG})$ molecular weight proteins to the alveolar spaces [50]. This phase contributes with a 40 -fold increase in lung $\alpha 1$-AT bioactivity and a 51 -fold increase in $\alpha 2-\mathrm{MG}$ concentration.

The second phase is contributed by the liver acute phase response that increases the capillary-alveolar concentration gradient for $\alpha 1-\mathrm{AT}$ and mainly for $\alpha 2$ MG. This phase provides an extra $18 \%$ increase in BALF $\alpha 1$-AT bioactivity and an extra $281 \%$ elevation in BALF $\alpha 2-$ MG concentration (above the high levels provided by the first phase of antiprotease enrichment found at $4 \mathrm{~h}$ ), in the context of significant reduction in total protein content in the same period of time. Interestingly, the antiprotease with the largest change in BALF in this phase is $\alpha 2-M G$ that has also the largest 
change in blood concentration and in liver mRNA expression.

This two-phase response in lung antiprotease enrichment is likely to be unique to this model and not easy to detect in other models of ALI, in which alveolarcapillary barrier derangement is delayed by depending more on the effects of the inflammatory response than on the direct early effect of the acidic component of gastric juice.

It is also possible that a small part of the lung enrichment in antiproteases may come from alveolar mononuclear cells, that are known to respond to inflammatory stimuli with a low grade local lung APR $[19,47]$. However, given the time-course of changes, this factor is unlikely to play a major role in our model, since antiprotease flooding occurs very early, prior to and during PMNn cell infiltration, and prior to mononuclear cell predominance, which occurs after day 4 [4, 5]. Furthermore it is accepted that the small amount of $\alpha 1$-AT released from monocytes serves more as a microenvironmental front line defense against proteases provided by the same monocytes [47].

On the basis of our results, local lung effects of gastric fluid damaging the alveolar-capillary barrier act in concert with lung inflammation-induced hepatic acute phase response to favour the arrival of new antiproteases to improve lung defense. Evidence of complex formation between $\alpha 1$-AT and elastase released from the inflammatory cells in the first $24 \mathrm{~h}$ provide support for the idea that antiprotease enrichment of the alveolar spaces plays a role limiting lung injury by proteases in this model. Protease inhibition may represent one of many mechanisms involved in the significant capacity of the lung to repair the severe ALI induced by gastric fluid recently reported by our group [5].

We postulate that antiprotease supplementation during the window of opportunity in which the hepatic APR co-exists with increased permeability, could be useful during ALI, in species without an increment in $\alpha 1$-AT and/or $\alpha 2-M G$ in the liver acute phase response. In addition, it could be possible that either liver diseases or polymorphisms in the acute phase response genes may constitute susceptibility factors for lung or other tissue injuries. In this regard, increased lethality from lung damage has been shown by Borzio et al. [56] in patients with liver cirrhosis. On the other hand, a reduced APR was implicated in the increased lethality observed in experimental cirrhosis [57]. In the light of our results it is possible that antiproteases as part of APR could be involved in the results of the above mentioned studies.

In addition, since the APPs in blood remain elevated for several days, it is likely that they may impact lung response to repetitive events of aspiration. Future studies of this response with different lung inflammatory stimuli should consider the evaluation of the full range of proteins that are co-expressed, including the antiproteases, in order to have a better appreciation of the net effects of the liver APR in lung defense.

\section{Conclusions}

Our results provide insights into the role of the liver in the pathogenesis of acute lung injury. A severe lung inflammatory reaction induced by gastric fluid elicits a liver acute phase response involving the main lung antiproteases. Liver changes act in concert with the derangement of the alveolar-capillary barrier to enrich the alveolar spaces with antiproteases. These results support the possibility of therapeutic interventions such as antiprotease supplementation during the window of opportunity in which the hepatic APR co-exists with increased permeability.

Acknowledgments

This research was supported by Grants 1120943 and 11140913 from FONDECYT (Fondo Nacional de Desarrollo Científico y Tecnológico) Chile.

\section{Authors' contributions}

PA: Involvement in conception, hypothesis delineation, acquisition of data, data analysis and interpretation, writing, substantial involvement in revision. MM: Acquisition of data, data analysis and interpretation. PO: Data analysis and interpretation, writing. RM: Acquisition of data, data analysis and interpretation. KD: Acquisition of data, data analysis and interpretation, writing. MR: Acquisition of data, data analysis and interpretation. GB: Involvement in conception, hypothesis delineation, design of the study, acquisition of data, data analysis and interpretation, writing, substantial involvement in revision. All authors read and approved the final manuscript.

Competing interests

The authors declare that they have no competing interests.

\section{Author details}

${ }^{1}$ Department of Respiratory Diseases and Medical Research Center, Faculty of Medicine, Pontificia Universidad Católica de Chile, Marcoleta 350, piso 1,

Santiago, Chile. ${ }^{2}$ Department of Nutrition, Diabetes and Metabolism, Faculty of Medicine, Pontificia Universidad Católica de Chile, Santiago, Chile. ${ }^{3}$ Department of Physiology, Faculty of Biological Sciences, Pontificia Universidad Católica de Chile, Santiago, Chile. ${ }^{4}$ Instituto Nacional del Tórax, Santiago, Chile.

Received: 4 December 2015 Accepted: 17 May 2016

Published online: 14 June 2016

\section{References}

1. Marik PE. Aspiration pneumonitis and aspiration pneumonia. N Engl J Med. 2001;344:665-71.

2. Raghavendran K, Nemzek J, Napolitano L, Knight PR. Aspiration-induced lung injury. Crit Care Med. 2011;39:818-26.

3. Tsai $C L$, Lin $Y H$, Wang MT, Chien LN, Jeng C, Chian CF, Perng WC, Chiang $\mathrm{CH}$, Chiou HY. Gastro-oesophageal reflux disease increases the risk of intensive care unit admittance and mechanical ventilation use among patients with chronic obstructive pulmonary disease: a nationwide population-based cohort study. Crit Care. 2015;19:110.

4. Appel JZ, Lee SM, Hartwig MG, Li B, Hsieh CC, Cantu E, Yoon Y, Lin SS, Parker W, Davis RD. Characterization of the innate immune response to chronic aspiration in a novel rodent model. Respir Res. 2007;8:87.

5. Araos J, Ayala P, Meneses M, Contreras R, Cutiño A, Montalva R, Tazelaar H, Borzone G. Resolution of lung injury after a single event of aspiration: a model of bilateral instillation of whole gastric fluid. Am J Pathol. 2015;185: 2698-708. 
6. Davidson BA, Knight PR, Wang Z, Chess PR, Holm BA, Russo TA, Hutson A, Notter RH. Surfactant alterations in acute inflammatory lung injury from aspiration of acid and gastric particulates. Am J Physiol Lung Cell Mol Physiol. 2005;288:699-708.

7. Downing TE, Sporn TA, Bollinger RR, Davis RD, Parker W, Lin SS. Pulmonary histopathology in an experimental model of chronic aspiration is independent of acidity. Exp Biol Med (Maywood). 2008;233:1202-12.

8. Kennedy TP, Johnson KJ, Kunkel RG, Ward PA, Knight PR, Finch JS. Acute acid aspiration lung injury in the rat: Biphasic pathogenesis. Anesth Analg. 1989:69:87-92.

9. Knight PR, Davidson BA, Nader ND, Helinski JD, Marschke CJ, Russo TA, Hutson AD, Notter RH, Holm BA. Progressive, severe lung injury secondary to the interaction of insults in gastric aspiration. Exp Lung Res. 2004;30:535-57

10. Knight PR, Druskovich G, Tait AR, Johnson KJ. The role of neutrophils, oxidants, and proteases in the pathogenesis of acid pulmonary injury. Anesthesiology. 1992:77:772-8.

11. Knight PR, Rutter T, Tait AR, Coleman E, Johnson K. Pathogenesis of gastric particulate lung injury: a comparison and interaction with acidic pneumonitis. Anesth Analg. 1993;77:754-60.

12. Mendelson $\mathrm{CL}$. The aspiration of stomach contents into the lungs during obstetric anesthesia. Am J Obstet Gynecol. 1946;52:191-205.

13. Patel BV, Wilson MR, Takata M. Resolution of acute lung injury and inflammation: a translational mouse model. Eur Respir J. 2012;39:1162-70.

14. Raghavendran K, Davidson BA, Mullan BA, Hutson AD, Russo TA, Manderscheid PA, Woytash JA, Holm BA, Notter RH, Knight PR. Acid and particulate-induced aspiration lung injury in mice: importance of mcp-1. Am J Physiol Lung Cell Mol Physiol. 2005;289:134-43.

15. Teabeaut JR. Aspiration of gastric contents; an experimental study. Am J Pathol. 1952;28:51-67.

16. Gabay C, Kushner I. Acute-phase proteins and other systemic responses to inflammation. N Engl J Med. 1999;340:448-54.

17. Goto K, Saito A, Nagase S, Sinohara H. Acute phase response of plasma proteins in analbuminemic rats. J Biochem. 1988;104:952-5.

18. Kataranovsky M, Magić Z, Pejnović N. Early inflammatory cytokine and acute phase protein response under the stress of thermal injury in rats. Physiol Res. 1999;48:473-82.

19. Hilliard KL, Allen E, Traber KE, Yamamoto K, Stauffer NM, Wasserman GA, Jones MR, Mizgerd JP, Quinton LJ. The lung-liver axis facilitates pulmonary innate immunity and hepatoprotection during pneumonia. Am J Respir Cell Mol Biol. 2015;53:378-90.

20. Renckens R, Roclofs JJTH, Knapp S, de Vos AF, Florquin S, van der Poll T. The acute-phase response and serum amyloid $A$ inhibit the inflammatory response to acinetobacter baumannii pneumonia. J Infect Dis. 2006;193: 187-95.

21. Matute-Bello G, Downey G, Moore BB, Groshong SD, Matthay MA, Slutsky AS, Kuebler WM. An official American Thoracic Society workshop report: features and measurements of experimental acute lung injury in animals. Am J Respir Cell Mol Biol. 2011;44:725-38.

22. Bradford MM. A rapid and sensitive method for the quantitation of microgram quantities of protein utilizing the principle of protein-dye binding. Anal Biochem. 1978;72:248-54.

23. Udaka K, Takeuchi Y, Movat HZ. Simple method for quantitation of enhanced vascular permeability. Proc Soc Exp Biol Med. 1970;133:1384-7.

24. Von Clauss A. Rapid physiological coagulation method in determination of fibrinogen. Acta Haematol. 1957;17:237-46.

25. Bieth J, Wermuth CG. The action of elastase on p-nitroanilide substrates. Biochem Biophys Res Commun. 1973;53:383-90.

26. Ying $\mathrm{QL}$, Simon SR. DNA from bronchial secretions modulates elastase inhibition by alpha(1)-proteinase inhibitor and oxidized secretory leukoprotease inhibitor. Am J Respir Cell Mol Biol. 2000;23:506-13.

27. Livak KJ, Schmittgen TD. Analysis of relative gene expression data using real-time quantitative PCR and the $2-\Delta \Delta C$ method. Methods. 2001;25:402-8.

28. Pfaffl MW. A new mathematical model for relative quantification in real-time RT-PCR. Nucleic Acids Res. 2001;29:2002-7.

29. Sokal RR, Rohlf FJ. Biometry. New York: WH Freeman; 1981.

30. Koj A, Hatton MW, Wong KL, Regoeczi E. Isolation and partial characterization of rabbit plasma alpha1-antitrypsin. Biochem J. 1978;169:589-96.

31. Stockley RA, Afford SC. The effect of leucocyte elastase on the immunoelectrophoretic behaviour of alpha 1-antitrypsin. Clin Sci (Lond). 1984;66:217-24
32. Merritt TA, Cochrane CG, Holcomb K, Bohl B, Hallman M, Strayer D, Edwards DK, Gluck L. Elastase and alpha1-proteinase inhibitor activity in tracheal aspirates during respiratory distress syndrome. Role of inflammation in the pathogenesis of bronchopulmonary dysplasia. J Clin Invest. 1983;72:656-66.

33. Heinrich PC, Castel V, Andus T. Interleukin- 6 and the acute phase response. Biochem J. 1990;265:621-36.

34. Van Eeden SF, Yeung A, Quinlam K, Hogg JC. Systemic response to ambient particulate matter: relevance to chronic obstructive pulmonary disease. Proc Am Thorac Soc. 2005;2:61-7.

35. Garcia-Rio F, Miravitlles M, Soriano JB, Muñoz L, Duran-Tauleria E, Sánchez G, Sobradillo V, Ancochea J, EPI-SCAN Steering Committee. Systemic inflammation in chronic obstructive pulmonary disease: a population-based study. Respir Res. 2010;11:63.

36. Bode JG, Albrecht U, Häussinger D, Heinrich PC, Schaper F. Hepatic acute phase proteins-regulation by IL-6- and IL-1-type cytokines involving STAT3 and its crosstalk with NF-kB-dependent signaling. Eur J Cell Biol. 2012;91: 496-505.

37. Janciauskiene S, Wrenger S, Welte T. Immunoregulatory Properties of Acute Phase Proteins - Specific Focus on a1-Antitrypsin. In: Janciauskiene S, editor. Immunology Allergology and Rheumatology. Intech. 2013. DOI: 10.5772/56393.

38. Hafeez W, Ciliberto G, Perlmutter DH. Constitutive and modulated expression of the human alpha 1 - antitrypsin gene. Different transcriptional initiation sites used in three different cell types. J Clin Invest. 1992;89:1214-22.

39. Morgan K, Scobie G, Marsters P, Kalsheker NA. Mutation in an alpha1antitrypsin enhancer results in an interleukin-6 deficient acute-phase response due to loss of cooperativity between transcription factors. Biochim Biophys Acta. 1997;1362:67-76.

40. Fattori E, Cappelletti M, Costa P, Sellitto C, Cantoni L, Carelli M, Faggioni R, Fantuzzi G, Ghezzi P, Poli V. Defective inflammatory response in interleukin 6-deficient mice. J Exp Med. 1994;180:1243-50.

41. Kopf M, Baumann H, Freer G, Freudenberg M, Lamers M, Kishimoto T, Zinkernagel R, Bluethmann H, Köhler G. Impaired immune and acute-phase responses in interleukin-6-deficient mice. Nature. 1994;368:339-42.

42. Kuribayashi T, Tomizawa M, Seita T, Tagate K, Yamamoto S. Relationship between production of acute phase proteins and strength of inflammatory stimulation in rats. Lab Anim. 2011:43:215-8.

43. Fujii T, Hayashi S, Hogg JC, Mukae H, Suwa T, Goto Y, Vincent R, van Eeden SF. Interaction of alveolar macrophages and airway epithelial cells following exposure to particulate matter produces mediators that stimulate the bone marrow. Am J Respir Cell Mol Biol. 2002;27:34-41.

44. Buff SM, Yu H, McCall JN, Caldwell SM, Ferkol TW, Flotte TR, Virella-Lowell IL. IL-10 delivery by AAV5 vector attenuates inflammation in mice with Pseudomonas pneumonia. Gene Ther. 2010;17:567-76.

45. Uskokovic A, Dinic S, Mihailovic M, Grigorov I, Ivanovic-Matic S, Bogojevic D, Grdovic N, Arambasic J, Vidakovic M, Martinovic V, Petrovic M, Poznanovic G. STAT3/NFkB interplay in the regulation of a2-macroglobulin gene expression during rat liver development and the acute phase response. IUBMB Life. 2007:59:170-8.

46. Mc Elvaney N, Crystal R. Antiproteases and lung defense. In: Crystal RG, West J, Weibel ER, Barnes PJ, editors. The lung: Scientific foundations. New York: Lippincott-Raven; 1997. p. 2219-35.

47. Knoell DL, Ralston DR, Coulter KR, Wewers MD. Alpha 1-antitrypsin and protease complexation is induced by lipopolysaccharide, interleukin-1 beta, and tumor necrosis factor-alpha in monocytes. Am J Respir Crit Care Med. 1998;157:246-55.

48. Suzuki Y, Yoshida K, Ichimiya T, Yamamoto T, Sinohara H. Trypsin inhibitors in guinea pig plasma: isolation and characterization of contrapsin and two isoforms of alpha-1-antiproteinase and acute phase response of four major trypsin inhibitors. J Biochem. 1990;107:173-9.

49. Daemen M, Heemskerk V, van't Veer C, Denecker G, Wolfs T, Vandenabeele $P$, Buurman W. Functional protection by acute phase proteins a1-acid glycoprotein and a1-antitrypsin against ischemia/reperfusion injury by preventing apoptosis and inflammation. Circulation. 2000;102:1420-6.

50. Holter JF, Weiland JE, Pacht ER, Gadek JE, Davis WB. Protein permeability in the adult respiratory distress syndrome. Loss of size selectivity of the alveolar epithelium. J Clin Invest. 1986;78:1513-22.

51. Kurdowska A, Carr FK, Stevens MD, Baughman RP, Martin TR. Studies on the interaction of IL-8 with human plasma alpha 2-macroglobulin: evidence for the presence of IL-8 complexed to alpha 2-macroglobulin in lung fluids of patients with adult respiratory distress syndrome. J Immunol. 1997;158: 1930-40. 
52. Ahyi AN, Quinton LJ, Jones MR, Ferrari JD, Pepper-Cunningham ZA, Mella $J R$, Remick DG, Mizgerd JP. Roles of STAT3 in protein secretion pathways during the acute-phase response. Infect Immun. 2013;81:1644-53.

53. Sakamori S, Takehara T, Ohnishi C, Tatsumi T, Ohkawa K, Takeda K, Akira S, Hayashi N. Signal transducer and activator of transcription 3 signaling within hepatocytes attenuates systemic inflammatory response and lethality in septic mice. Hepatology. 2007;46:1564-73.

54. Quinton $L$, Jones MR, Robson BE, Mizgerd JP. Mechanisms of the hepatic acute-phase response during bacterial pneumonia. Infect Immun. 2009;77: 2417-26.

55. Quinton LJ, Blahna MT, Jones MR, Allen E, Hilliard KL, Ferrari JD, Zhang X, Sabharwal V, Algul H, Akira S, Schmid RM, Pelton SI, Spira A, Mizgerd JP. Combined hepatocyte-specific targeting of NF-kB RelA and STAT3 abrogates the acute phase response in mice. J Clin Invest. 2012;122: 1758-63.

56. Borzio M, Salerno F, Piantoni L, Cazzaniga M, Angeli P, Bissoli F, Boccia S, Colloredo-Mels G, Corigliano P, Fornaciari G, Marenco G, Pistara R, Salvagnini M, Sangiovanni A. Bacterial infection in patients with advanced cirrhosis: a multicentre prospective study. Dig Liver Dis. 2001;33:41-8.

57. Nielsen SS, Grøfte T, Tygstrup N, Vilstrup H. Synthesis of acute phase proteins in rats with cirrhosis exposed to lipopolysaccharide. Comp Hepatol. 2006:5:3.

\section{Submit your next manuscript to BioMed Central} and we will help you at every step:

- We accept pre-submission inquiries

- Our selector tool helps you to find the most relevant journal

- We provide round the clock customer support

- Convenient online submission

- Thorough peer review

- Inclusion in PubMed and all major indexing services

- Maximum visibility for your research

Submit your manuscript at www.biomedcentral.com/submit 